LBL-36614

\title{
Progress on Flow Visualization and Relative Permeability Measurement in Transparent Replicas of Natural Fractures from Yucca Mountain
}

\author{
P. Persoff, K. Pruess, and L.P. Petersen
}

Earth Sciences Division

Lawrence Berkeley Laboratory,

University of California

Berkeley, CA 94720

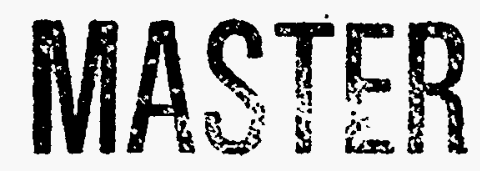

This work was supported by the U.S. Department of Energy, Office of Civilian Radioactive Waste Management, administered by the DOE Nevada Office in cooperation with the United States Geological Survey, Denver, under Contract No. DE-AC03-76SF00098. 


\begin{abstract}
Small sections ( $75 \mathrm{~mm} \times 75 \mathrm{~mm}$ ) of two natural rock fractures from outcrop boulders of Tiva Canyon tuff have been reproduced as transparent replicas. Aperture maps were drawn from images of the replicas filled with dye. Apertures were measured by the areas occupied by liquid drops of known volume. For both these fractures, the average aperture is about $350 \mu \mathrm{m}$, while the hydraulic aperture is less $(72$ and $130 \mu \mathrm{m})$. Two-phase (air-water) flow experiments have been conducted in these replicas to measure relative permeability and capillary pressures. The results obtained confirm the results of previous fracture experiments, and theoretical analysis, that the sum of relative permeabilities is much less than $I$ at intermediate saturations.
\end{abstract}

\title{
Introduction
}

The welded tuffs in the vadose zone of Yucca Mountain, Nevada, are being investigated as the potential site of a geologic repository for high-level nuclear wastes. The suitability of this site depends upon minimizing the possibility of aqueous transport of radionuclides from the wastes to the environment. The repository location has been chosen for its isolation by low-permeability rock from both the surface and the water table, in a desert area of low precipitation. The welded tuffs have very low (nanodarcymicrodarcy) permeability, offering protection from flowing groundwater.

The repository horizon, although of low permeability, is known to be fractured, suggesting the possibility of fast paths for contaminant transport. As part of the repository evaluation, this study has been undertaken to characterize typical fractures from Yucca Mountain tuffs. Another purpose of this study is to gain insight into pore-level phenomena occurring during multi-phase flow in fractures generally. For this reason measurements were made not in the actual fractures, but in identical transparent replicas that reproduce the fracture void geometry. Use of transparent replicas allows observation of displacement phenomena and estimation of fracture saturation.

Two aspects of fracture characterization are examined in this work: measurement of relative permeability of the fractures to wetting and nonwetting phases (water and nitrogen gas in these experiments) and characterization of void space geometry as a "map" of aperture space over the samples (75 mm x $75 \mathrm{~mm}$ ).

Sits

Samples

Nine outcrop boulders (see Table 1) from Fran Ridge and Yucca Mountain containing natural fractures were collected with the guidance and assistance of Alan Flint of the USGS. The fractures were pried open in the laboratory and photographed. Six of the rocks provided fractures that were sufficiently

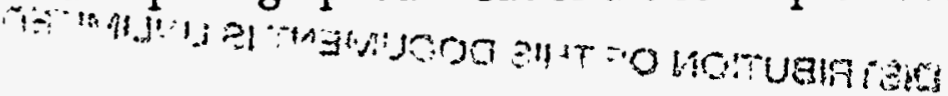




\section{DISCLAIMER}

This report was prepared as an account of work sponsored by an agency of the United States Government. Neither the United States Government nor any agency thereof, nor any of their employees, make any warranty, express or implied, or assumes any legal liability or responsibility for the accuracy, completeness, or usefulness of any information, apparatus, product, or process disclosed, or represents that its use would not infringe privately owned rights. Reference herein to any specific commercial product, process, or service by trade name, trademark, manufacturer, or otherwise does not necessarily constitute or imply its endorsement, recommendation, or favoring by the United States Government or any agency thereof. The views and opinions of authors expressed herein do not necessarily state or reflect those of the United States Government or - any agency thereof. 


\section{DISCLAIMER}

Portions of this document may be illegible in electronic image products. Images are produced from the best available original document. 
planar to be usable for these experiments. Several of the fractures were found to be coated with minerals, indicating water flow. Fracture YM-3 had a non-calcitic mineral coating, while one side of fracture YM-4 was about 50\% coated with a calcitic mineral coating over a non-calcitic coating. These fracture surfaces are rougher than those from Stripa and Dixie Valley that have been studied previously. Transparent epoxy replicas of the fractures YM-1, 3- and 4 were made using molding and casting techniques described in Persoff and Pruess (1994). The fracture replicas were machined to 3-inch squares to fit the apparatus. Two-phase flow experiments were done using replicas of YM-3 and YM-4. The actual rock fractures YM-3 and YM-4 were also machined to fit the endcaps in preparation for further experiments.

Table 1. Natural fracture samples used in these experiments.

\begin{tabular}{|l|l|l|}
\hline Sample & Location & Formation \\
\hline YM-1 & $\begin{array}{l}\text { NE side of dune wash, } \\
\text { west of Fran ridge }\end{array}$ & $\begin{array}{l}\text { upper cliff of Topopah } \\
\text { Springs welded }\end{array}$ \\
\hline YM-2 & $\begin{array}{l}\text { NE side of dune wash, } \\
\text { west of Fran ridge }\end{array}$ & Tiva Canyon welded \\
\hline YM-3 & $\begin{array}{l}\text { NE side of dune wash, } \\
\text { west of Fran ridge }\end{array}$ & $\begin{array}{l}\text { Tiva Canyon columnar } \\
\text { transition zone }\end{array}$ \\
\hline YM-4 & $\begin{array}{l}\text { NE side of dune wash, } \\
\text { west of Fran ridge }\end{array}$ & $\begin{array}{l}\text { Tiva Canyon welded } \\
\text { columnar }\end{array}$ \\
\hline YM-5 & near NRG-6 site & $\begin{array}{l}\text { lower lithophysal of the } \\
\text { Tiva Canyon welded }\end{array}$ \\
\hline YM-6 & NRG-5 & Tiva Canyon welded \\
\hline YM-7 & & Tiva Canyon welded \\
\hline YM-8 & at UZ-6, top of YM & Topopah Springs upper \\
\hline$Y M-9$ & &
\end{tabular}

Single- and Two-phase Flow measurements.

Flow measurements were done using the apparatus and techniques described elsewhere (Persoff and Pruess 1994, Persoff et al. 1994). Essentially, the Hassler method for relative permeability measurements in porous cores was modified for fractures. This technique provides for capillary separation of the phases at inlet and outlet, and allows the capillary pressures to be measured and controlled as an independent experimental variable.

Fracture replicas were assembled to endcaps, and gas permeability was measured. Then they were flushed with $\mathrm{CO}_{2}$ gas and then saturated with water, and liquid permeability measurements were made. Dye was introduced to identify fast flow paths; this also provided another opportunity to identify areas of large and small apertures and asperities. Then gas and liquid were injected simultaneously for two-phase flow measurements. Table 2 summarizes previously reported experiments (A-D) and the experiments reported here (E and $F)$ 
Table 2. Two-phase flow experiments in rough-walled fractures.

\begin{tabular}{|l|l|l|l|l|}
\hline $\begin{array}{l}\text { Expt } \\
\text { (hydrodynamic } \\
\text { aperture) }\end{array}$ & $\begin{array}{l}\text { Gas } \\
\text { injection }\end{array}$ & $\begin{array}{l}\text { Liquid } \\
\text { injection }\end{array}$ & Data presentation \\
\hline A & $\begin{array}{l}\text { Stripa replica 1 } \\
(8.5 \mu \mathrm{m})\end{array}$ & $\begin{array}{l}\text { constant } \\
\text { mass } \\
\text { rate }\end{array}$ & $\begin{array}{l}\text { constant } \\
\text { volume } \\
\text { rate }\end{array}$ & $\begin{array}{l}\text { Data in Persoff et al., 1991, } \\
\text { and Persoff and Pruess } \\
1994\end{array}$ \\
\hline B & $\begin{array}{l}\text { Stripa replica 2 } \\
(17.8 \mu \mathrm{m})\end{array}$ & $\begin{array}{l}\text { constant } \\
\text { mass } \\
\text { rate }\end{array}$ & $\begin{array}{l}\text { constant } \\
\text { volume } \\
\text { rate }\end{array}$ & $\begin{array}{l}\text { Videotape observations of } \\
\text { liquid slug motion }\end{array}$ \\
\hline C & $\begin{array}{l}\text { Stripa natural } \\
\text { rock }(21.7 \mu \mathrm{m})\end{array}$ & $\begin{array}{l}\text { constant } \\
\text { mass } \\
\text { rate }\end{array}$ & $\begin{array}{l}\text { constant } \\
\text { volume } \\
\text { rate }\end{array}$ & $\begin{array}{l}\text { Data in Persoff and Pruess } \\
\text { 1993, and Persoff and } \\
\text { Pruess 1994 }\end{array}$ \\
\hline D & $\begin{array}{l}\text { Dixie Valley } \\
\text { replica }(8.5 \mu \mathrm{m})\end{array}$ & $\begin{array}{l}\text { constant } \\
\text { pressure }\end{array}$ & $\begin{array}{l}\text { constant } \\
\text { volume } \\
\text { rate }\end{array}$ & $\begin{array}{l}\text { Data in Persoff and Pruess } \\
1993, \text { and Persoff and } \\
\text { Pruess 1994 }\end{array}$ \\
\hline E & $\begin{array}{l}\text { Yucca Mountain } \\
\text { replica 3 (72 } \mu \mathrm{m})\end{array}$ & $\begin{array}{l}\text { constant } \\
\text { pressure }\end{array}$ & $\begin{array}{l}\text { constant } \\
\text { volume } \\
\text { rate }\end{array}$ & $\begin{array}{l}\text { Data in Figs. 1, 3, 5, } \\
\text { 7, 9, an d 11. }\end{array}$ \\
\hline F & $\begin{array}{l}\text { Yucca Mountain } \\
\text { replica 4 (130 } \\
\mu \mathrm{m})\end{array}$ & $\begin{array}{l}\text { constant } \\
\text { pressure }\end{array}$ & $\begin{array}{l}\text { constant } \\
\text { volume } \\
\text { rate }\end{array}$ & $\begin{array}{l}\text { Data in Figs. 2, 4, 6, } \\
8,10, \text { and 12. }\end{array}$ \\
\hline
\end{tabular}

Table 3. Summary of data series run in experiments E and F.

\begin{tabular}{|l|l|l|l|l|}
\hline Experimert & Series & $\begin{array}{l}\text { Liquid Flow rate } \\
\text { Range }(\mathrm{mL} / \text { min.) }\end{array}$ & $\begin{array}{l}\text { Gas Flow rate } \\
\text { Range }(\mathrm{mL} / \mathrm{min} .)\end{array}$ & $\begin{array}{l}\text { Saturation } \\
\text { Direction }\end{array}$ \\
\hline $\mathrm{E}$ & 0 & $0.03-0.1$ & $64-402$ & drying \\
\hline $\mathrm{E}$ & 1 & $0.004-0.03$ & $9-120$ & drying \\
\hline $\mathrm{E}$ & 2 & 0.004 & $33-115$ & wetting \\
\hline $\mathrm{E}$ & 3 & $0.003-0.1$ & $39-52$ & P $_{\mathrm{C}}=$ constant \\
\hline $\mathrm{F}$ & 0 & 0.04 & 95 & \\
\hline $\mathrm{F}$ & 1 & 0.015 & $12-85$ & drying \\
\hline $\mathrm{F}$ & 2 & 0.015 & $15-40$ & drying \\
\hline $\mathrm{F}$ & 3 & $0.0075-0.03$ & $40-55$ & wetting \\
\hline
\end{tabular}




\section{Experiment E (YM-3)}

Four series of data were collected. In series 0 and 1 , gas injection pressure was increased stepwise while generally holding liquid flow rate constant, so that capillary pressure and pressure.drop across the fracture increased in a drying regime. In series 0 , higher flow rates were used, and capillary control of pore occupancy was not complete; certain regions alternated between being occupied by gas and by liquid. In series 1 flow rates of both phases were lower, and pore occupancy was stable. In series 2 the capillary pressure was reduced stepwise, exploring the same range of capillary pressures under a wetting regime. The gas and liquid relative permeabilities (calculated from measured flow rates and pressures) increased and decreased respectively with increasing capillary pressure for each series, but when data from all series were compiled, the relative permeabilities were not unique functions of capillary pressures. To further investigate this observation, series 3 was run in which the capillary pressure was kept constant while varying the flow rates. Measurements from series 3 reproduced the data from the previous series.

\section{Experiment F (YM-4)}

In this experiment, special attention was paid to maintaining pore occupancy as steady as possible. Series 0 was a single data point. series 1 was run by holding the liquid flow rate constant and increasing the gas injection pressure stepwise to investigate a range of capillary pressures in a drying regime. Gas injection pressure was increased until the pore occupancy was no longer steady. Reduction of gas injection pressure to restore stable pore occupancy was not effective until the capillary pressure was reduced to $0.15 \mathrm{psi}$. Therefore, series 2 was not done by reducing the gas injection pressure and capillary pressure, but by increasing it (repeating the scheme of series 1 ) until stable pore occupancy was no longer possible. Finally, series 3 was done by increasing the liquid flow rate stepwise to reduce the capillary pressure; it too was continued until stable pore occupancy was no longer possible.

Permeability calculation. Fracture permeability is calculated from inlet and outlet pressures and flow rates, using modifications of the formulas for porous media (Persoff and Pruess 1994). In effect, one calculates the permeability $k$ of the sample as if it were a porous medium of thickness $h$. The quantity $h$ can also be thought of as the distance between uniformly spaced parallel fractures. For any set of pressure and flow rate data, the product $h k$ is independent of the sample thickness and represents the permeability-thickness of the fracture. The calculated hydrodynamic apertures are shown in Table 2. 
The permeability of a porous medium to gas is calculated by (Scheidegger, 1974)

$$
\mathrm{k}_{\mathrm{g}}=\frac{2 \mathrm{q}_{\mathrm{o}} \mu \mathrm{L} \mathrm{p}_{\mathrm{o}}}{\mathrm{p}_{\mathrm{i}}^{2}-\mathrm{p}_{\mathrm{o}}^{2}}
$$

where $k$ is permeability, $q$ is the darcy flow velocity or volumetric flux [L/t $]$, $\mu$ is the viscosity, $L$ is the length from inlet to outlet, subscripts $i$ and o represent inlet and outlet conditions, respectively, and subscript $g$ refers to gas. If flow is not through a porous medium but through a series of parallel fractures with spacing $h$, then both sides of equation (3) can be multiplied by $h$ to give

$$
\mathrm{hk}_{\mathrm{g}}=\frac{2 \mathrm{hq}_{\mathrm{o}} \mu \mathrm{Lp}_{\mathrm{o}}}{\mathrm{p}_{\mathrm{i}}{ }^{2}-\mathrm{p}_{\mathrm{o}}{ }^{2}}
$$

Without knowledge of the fracture aperture, the value of $q_{o}$ is not known, but the value of $\mathrm{hq}_{\mathrm{o}}$ is known from continuity:

$$
\mathrm{hq}_{\mathrm{o}}=\frac{\mathrm{Q}_{\mathrm{o}}}{\mathrm{w}}
$$

where $Q$ is the volumetric flow rate $\left[\mathrm{L}^{3} / \mathrm{t}\right]$ and $\mathrm{w}$ is the length of the fracture edge at inlet and outlet. Similarly, $\mathrm{kL}_{\mathrm{L}}$ cannot be measured, but $\mathrm{hkL}$ can be:

$$
\mathrm{hk}_{\text {liq }}=\frac{\mathrm{hq} \mu \mathrm{L}}{\mathrm{p}_{\mathrm{i}}-\mathrm{p}_{\mathrm{o}}}
$$

where $h q=\frac{Q}{W}$; for incompressible fluids $Q$ and $\mathrm{q}$ do not vary from inlet to outlet.

The effective hydrodynamic aperture of the fracture can be estimated from the data using the cubic law: the permeability of a parallel plate aperture of thickness $b$ is $b^{2} / 12$ (Witherspoon et al., 1980). If a series of plane parallel fractures with aperture $b$ are separated by distance $h$, then the average permeability of the fractured medium is $\left(b^{2} / 12\right)(b / h)$. Then

$\mathrm{b}=\sqrt[3]{12 \mathrm{kh}}$

Relative permeabilities were calculated as ratios of the measured effective $h k$ for gas and liquid to the $h k$ measured for single-phase liquid flow . To calculate ratios of gas and liquid flow rates, the volumetric gas flow rate was evaluated at the arithmetic average of the inlet and outlet gas 
pressures. Because the injected gas was dry, some evaporation of water occurred during flow through the fractures. For permeability calculations, we assumed that gas was equilibrated with water in the inlet endcaps (i.e., entered the fracture at $100 \%$ relative humidity). Calculated permeabilities are not sensitive to this assumption.

\section{Comparison with samples previously studied}

Single-phase (both gas and liquid) flow measurements showed that the fracture permeability was greater than those measured previously. This appears to result from the greater roughness of the surfaces. In both YM-3 and $\mathrm{YM}-4$, large areas of asperity were noted, amounting to about $10 \%$ of the area (see section on aperture mapping below). Dye tracer studies identified the fast flow paths. Again contrast was noted with a previous dye tracer study done in a fracture from Dixie Valley. In the Dixie Valley fracture the fast flow paths were clearly defined and narrow, but in these fractures the fast flow paths filled wide areas of approximately uniform aperture.

The greater hydraulic aperture and permeability of these fractures compared with those studied previously made some measurements more difficult. We found it difficult to maintain capillary separation of the phases at the outlet at capillary pressures less than $0.1 \mathrm{psi}$, and this condition made it difficult to measure high values of liquid relative permeability (above 0.1). Previously (Exp. D) we were able to cause stepwise gas invasion by increasing the gas injection pressure in small steps, and to observe the increase in liquid pressure drop resulting from a constant liquid flow rate. In fractures YM-3 and $Y M 4$, however, gas penetrated completely through the fracture with the first step increase of gas injection pressure.

With the larger apertures, the range of flow rates in which pore occupancy was strictly controlled by capillary forces is more restricted. Before initial gas invasion, the outlet gas pressure tap was disconnected, to prevent its becoming filled with liquid. When the outlet gas pressure tap was connected, the outlet gas pressure was reduced for a few seconds from $15 \mathrm{psi}$ to $14.3 \mathrm{psi}$. During this period of time, the gas pressure gradient was suddenly increased and the two phases flowed without capillary control in the regime described by Fourar et al (1993) as "complex". Capillary control was regained when the outlet gas pressure was raised and gas flow rate reduced. When the two phases flow with capillary control of pore occupancy, pore occupancy is completely stable, changing only in response to changes in boundary conditions. Under some conditions we observed situations in which pore occupancy was stable everywhere in the fracture replica except at one small region where occupancy would flicker back and forth between the two phases. This region, alternating between carrying gas and liquid phases, could add significantly to the measured permeability of both phases. 


\section{Results and Discussion}

All primary measured data are summarized in Appendix A. From these data, relative permeabilities were calculated as described above. One of the goals of this work was to find correlations that would permit estimation or prediction of relative permeabilities in terms of some other quantity. In previous work (Persoff et al 1991, 1993) correlations against capillary pressure and gas:liquid flow rate ratio were found; also desired is a correlation against liquid saturation. Measurements of liquid saturation have not been made, but analysis of aperture maps (see below) and video images taken during the flow measurements could in principle be used to calculate liquid saturation. Relative permeabilities for YM-3 and YM-4 are plotted as functions of measured capillary pressure in Figures 1 and 2, respectively. (Refer to Table 1 for directions of change during each data series.)

Figure 1 shows that during each series of measurements, gas and liquid relative permeabilities respectively increased and decreased with increasing capillary pressure. During series 0 , which was conducted at higher flow rates, capillary control of pore occupancy was not complete; some parts of the fracture alternated between carrying gas and liquid. This condition appears to enhance liquid transport. In series 3 (indicated by $x$ 's) liquid permeability decreased and gas permeability increased as both liquid flow rate and gas injection pressure were reduced stepwise to maintain a constant capillary pressure.

Figure 2 shows that the same pattern was found in experiment $F$ in replica YM-4 for the liquid phase, although the gas phase relative permeability data are suspect. In this experiment, capillary control was complete for all data points, and the enhanced liquid transport observed in experiment $E$, series 0 was not seen.

In Figures 3 and 4 relative permeabilities for YM-3 and YM-4, respectively, are plotted as functions of gas:liquid flow rate ratio. In both Figures 1 and 3 , points for series 1 and 2 show effects of drying-wetting hysteresis. All the data in Figures 1 through 4 confirm the results previously obtained, that the sum of gas and liquid relative permeabilities is much less than 1.

In Figures 5 and 6 , the relative permeabilities to gas and liquid are plotted against each other. These results show that the sum of the relative permeabilities is much less than 1, although the non-uniqueness of the relationships is also reflected here.

The data shown in Figures 1 through 4 indicate that relative permeabilities are not unique functions of capillary pressure or flow rate. This may reflect hysteresis in that several excursions were made between 
wetting and drying conditions. Theoretical analysis by Pruess and Tsang (1990) indicates that in a two-dimensional porous medium, or in a fracture, phase interference tends to be greater than in three-dimensional porous media, because fewer alternative flow paths are available. It appears that the same effect could cause the effect of hysteresis to be greater in a fracture than in three-dimensional porous media.

\section{Aperture Mapping}

Aperture maps are useful for interpreting flow measurements and visual observations, and for statistical description of fractures. Aperture maps of fractures YM-3 and YM-4 were produced by combining two different methods: light attenuation by dye (Nicholl and Glass, 1994) and area occupied by known volume (Hakami, 1988). In the first method, the replicas were filled with dye and digitally imaged with a video camera. The resulting image, darker where aperture is greater, gives a good map of the relative size of the aperture at every point in the fracture. Figures 7 and 8 are the images of fracture replicas YM-3 and YM-4, respectively, filled with dyed water. A feature of these replicas, evident in Figures 7 and 8, that differs from replicas previously studied is that the aperture appears to be uniform over wide areas with sharply defined edges, but locally changes rapidly to a much different aperture. This quality (a "paint by numbers" style of variation rather than smoothly varying) makes it easy to distinguish between areas of large and small aperture, and allows significant contours to be drawn by hand from the image, but only relative aperture information is obtained. Figures 9 and 10 were traced by hand from these images, with the colors representing different shades of darkness, corresponding to aperture levels. In the past, calibration of this method to yield absolute values of fracture aperture has been problematic. Therefore the method of light attenuation by dye was supplemented by measuring the area occupied by liquid drops of known volume placed at many points in the fracture and compressed by the same load as used in the flow experiments. Photographs of the compressed drops, also containing a scale, were projected onto graph paper, and the area occupied by each drop was estimated by counting squares. Approximately 150 drops were measured this way in each replica, and the aperture (drop volume divided by area) was assigned to the center of the drop. Contour maps of the calculated aperture were interpolated from these data, and are plotted in Figures 11 and 12. The aperture values contained in these Figures were used to assign aperture values to the areas identified in Figures 9 and 10.

\section{Summary}

Small sections ( $75 \mathrm{~mm} \times 75 \mathrm{~mm}$ ) of two natural rock fractures from outcrop boulders of Tiva Canyon tuff have been reproduced as transparent replicas. The transparent replicas were used to map the aperture distributions in the fractures and to measure absolute and relative permeabilities. 
For aperture mapping, the replicas were filled with liquid (both dyed and undyed water) and digitally imaged by a video camera. This allowed regions of relatively large and small aperture to be easily identified, but provided no data on the absolute aperture value. The absolute aperture at about 150 points in each replica was measured by the areas occupied by liquid drops of known volume. Information from both these methods was combined to draw aperture maps of the two replicas. For both these fractures, the average aperture is about $350 \mu \mathrm{m}$, while the hydraulic aperture is less (72 and $130 \mu \mathrm{m}$ ). These hydraulic apertures are larger than the apertures in other samples (Stripa granite and Dixie Valley tuff) that have been previously studied.

Two-phase (air-water) flow experiments have been conducted in these replicas to measure relative permeability and capillary pressures. The results obtained confirm the results of previous fracture experiments, and theoretical analysis, that the sum of relative permeabilities is much less than 1 at intermediate saturations.

\section{Acknowledgment}

This work was supported by the Office of Civilian Radioactive Waste Management administered by the DOE Nevada Office in cooperation with the United States Geological Survey, Denver; under Contract No. DE-AC0376SF00098. We thank Alan Flint of the USGS for assistance in obtaining the fracture samples, and our colleagues Curt Oldenburg and Jiamin Wan for reviewing the manuscript, and suggesting improvements. 


\section{References}

Fourar, M., S. Bories, R. Lenormand, and P. Persoff, Two-Phase Flow in Smooth and Rough Fractures: Measurement and Correlation by PorousMedium and Pipe-Flow Models, Water Resources Research, 29,(11), 3699-3708, 1993.

Hakami, E. Water Flow in Single Rock Joints, Licentiate Thesis 1988:11 L, Luleå University of Technology, Luleå, Sweden, November 1988.

Nicholl, M.J. and R. J. Glass "Wetting Phase Permeability in a Initially Wet Partially Saturated Horizontal Fracture" High Level Radioactive Waste Management : Proceedings of the Fifth International Conference, Las Vegas NV, May 22-26, 1994, vol 4, p 2007-2019, American Society of Civil Engineers, New York, 1994.

Persoff, $\mathrm{P}$ and Pruess, K. Two-Phase Flow Visualization and Relative Permeability Measurement in Transparent Replicas of Rough-Walled Rock Fractures, submitted to Water Resources Research (LBL-35279) June 1994

Persoff, P., K. Pruess, and L. Myer, Method and Apparatus for Determining Two-Phase Flow in Rock Fracture, U.S. Patent 5,311,766, May 17, 1994.

Persoff, P. and K. Pruess, Flow Visualization and Relative Permeability Measurements in Rough-Walled Rock Fractures, High Level Radioactive Waste Management : Proceedings of the Fourth International Conference, Las Vegas NV, April 26-28, 1993, vol. 2, 20332041, American Society of Civil Engineers, New York, 1993 (LBL-33447).

Persoff, P., K. Pruess, and L. Myer, Two-Phase Flow Visualization and Relative Permeability Measurements in Transparent Replicas of RoughWalled Rock Fractures, Proceedings, Sixteenth Workshop on Geothermal Reservoir Engineering, Stanford Univ., Stanford, CA., Jan. 23-25, 1991.

Pruess, K., and Y.W. Tsang, On Two-Phase Relative Permeability and Capillary Pressure of Rough-Walled Rock Fractures, Water Resources Research, 26 (9), 1915-1926, 1990.

Scheidegger, A.E., The Physics of Flow Through Porous Media,3rd ed., University of Toronto Press, Toronto, 102, 1974. 


\section{Figure Captions}

Figure 1. Relative permeability plotted against capillary pressure, experiment E, fracture replica YM-3.

Figure 2. Relative permeability plotted against capillary pressure, experiment F, fracture replica YM-4.

Figure 3. Relative permeability plotted against gas:liquid mass flow ratio, experiment $\mathrm{E}$, fracture replica $\mathrm{YM}-3$.

Figure 4. Relative permeability plotted against gas:liquid mass flow ratio, experiment $F$, fracture replica $Y M-4$.

Figure 5. Gas and liquid relative permeabilities plotted against each other, experiment E, fracture replica YM-3.

Figure 6. Gas and liquid relative permeabilities plotted against each other, experiment $F$, fracture replica YM-4.

Figure 7. Image of fracture replica filled with dye and photographed by transmitted light, replica YM-3.

Figure 8. Image of fracture replica filled with dye and photographed by transmitted light, replica YM-4.

Figure 9. Contours of relatively large and small aperture drawn by hand from image in Figure 7; replica YM-3. Colors representing aperture values were taken from Figure 11.

Figure 10. Contours of relatively large and small aperture drawn by hand from image in Figure 8; replica YM-4. Colors representing aperture values were taken from Figure 12.

Figure 11. Contours of aperture interpolated between 150 points calculated from measured area occupied by compressed liquid drops of known volume, replica YM-3.

Figure 12. Contours of aperture interpolated between 150 points calculated from measured area occupied by compressed liquid drops of known volume, replica YM-4. 

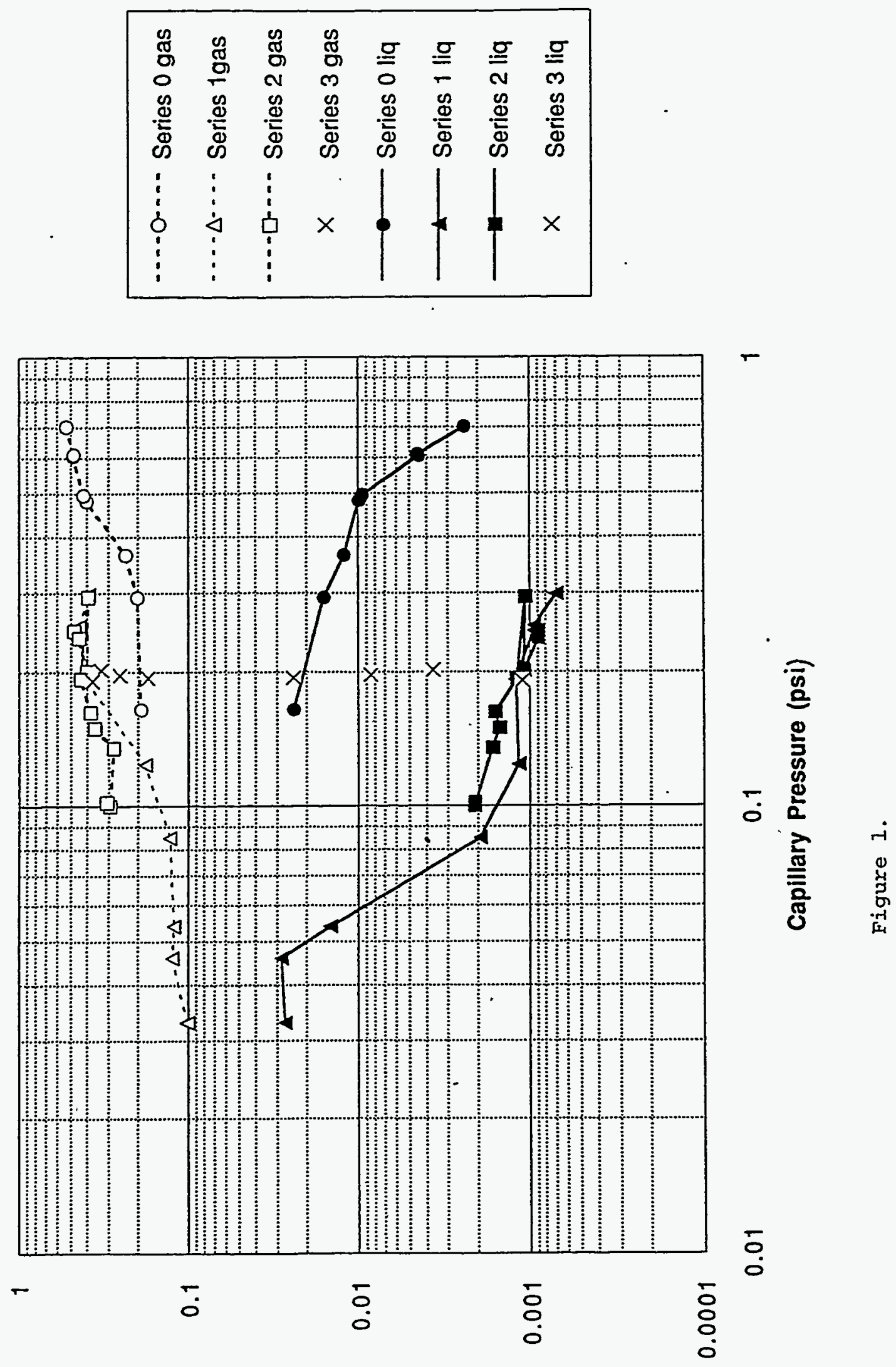

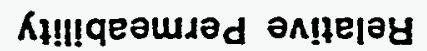




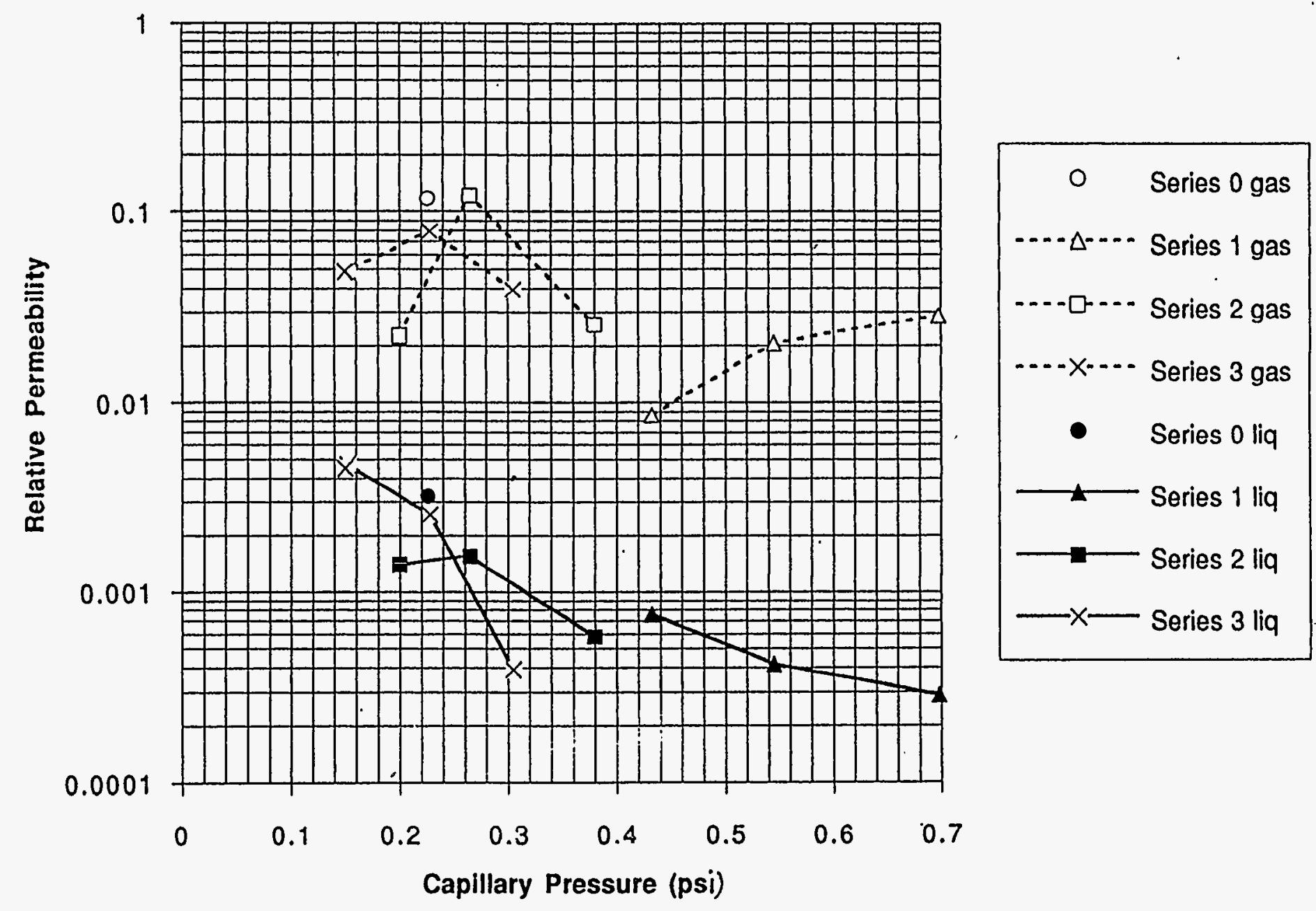

Figure 2. 

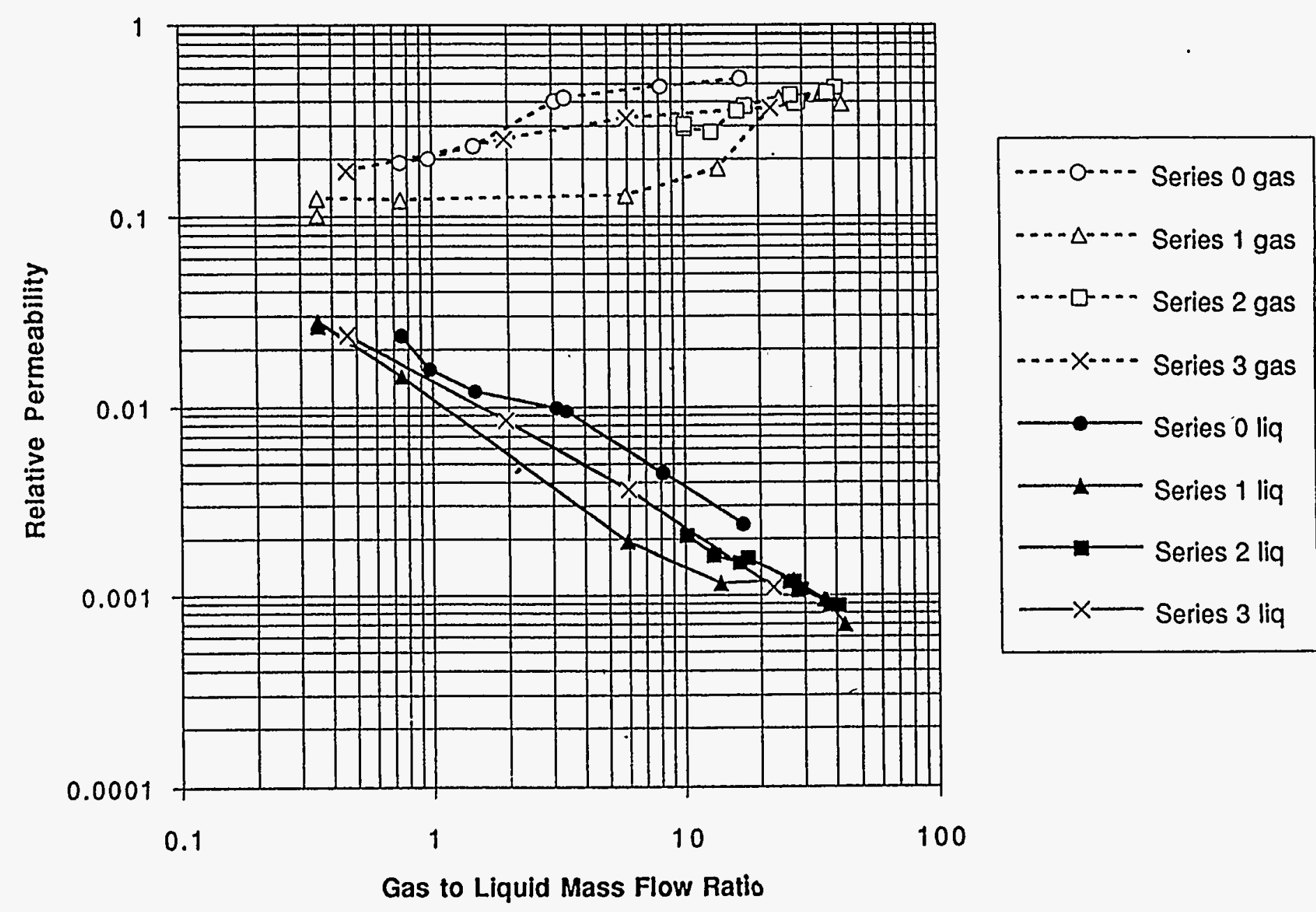

Figure 3. 

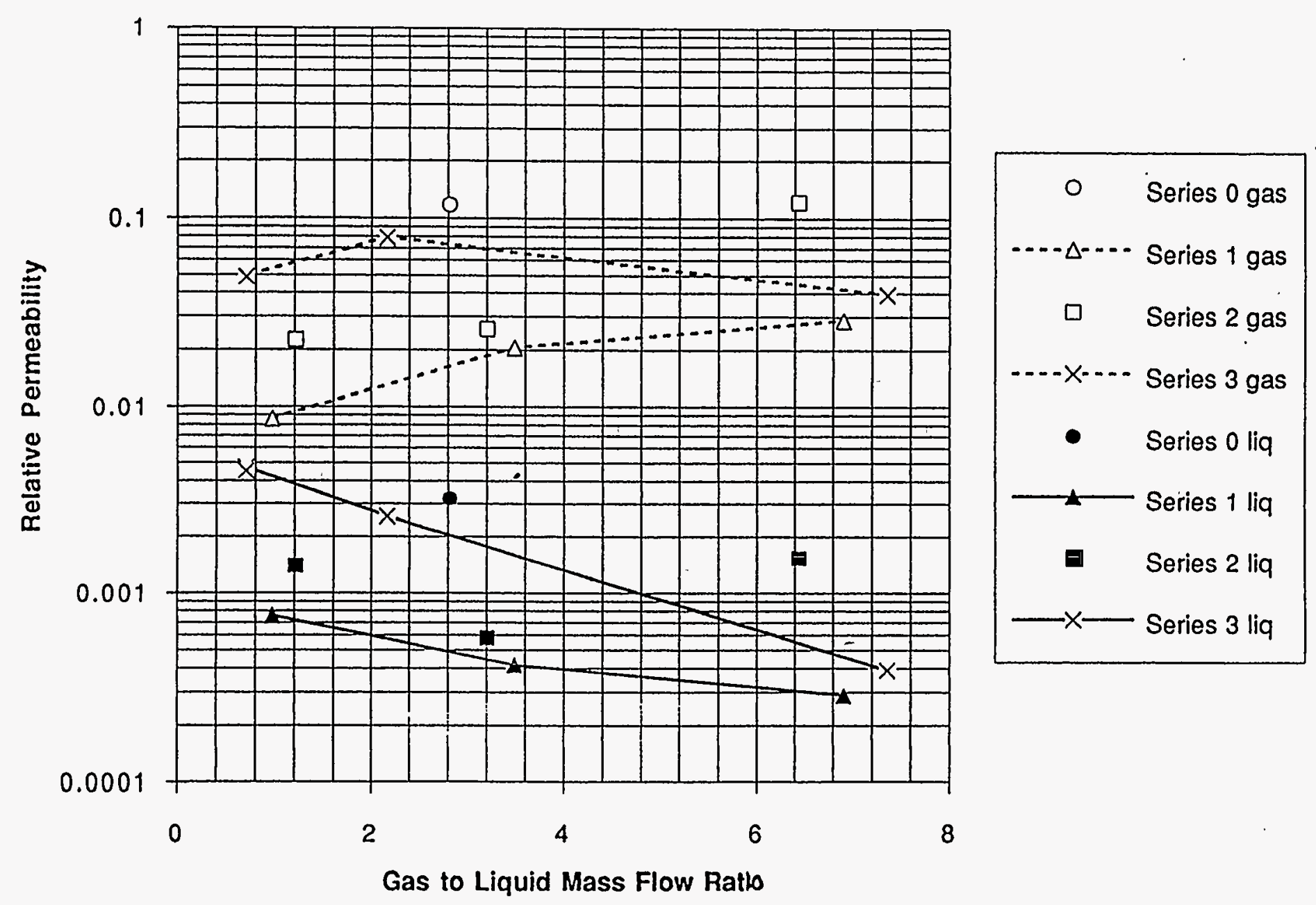

Figure 4. 

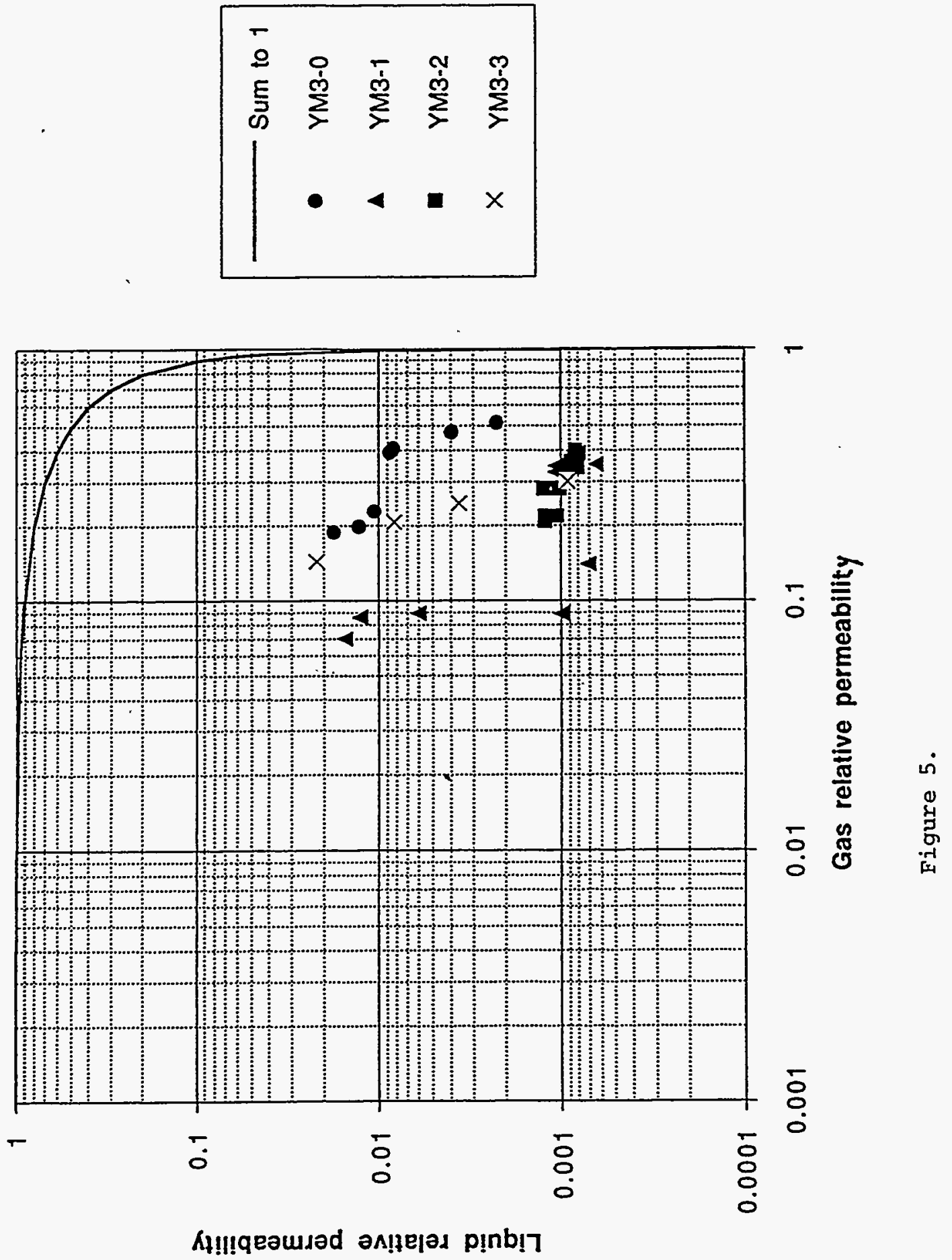

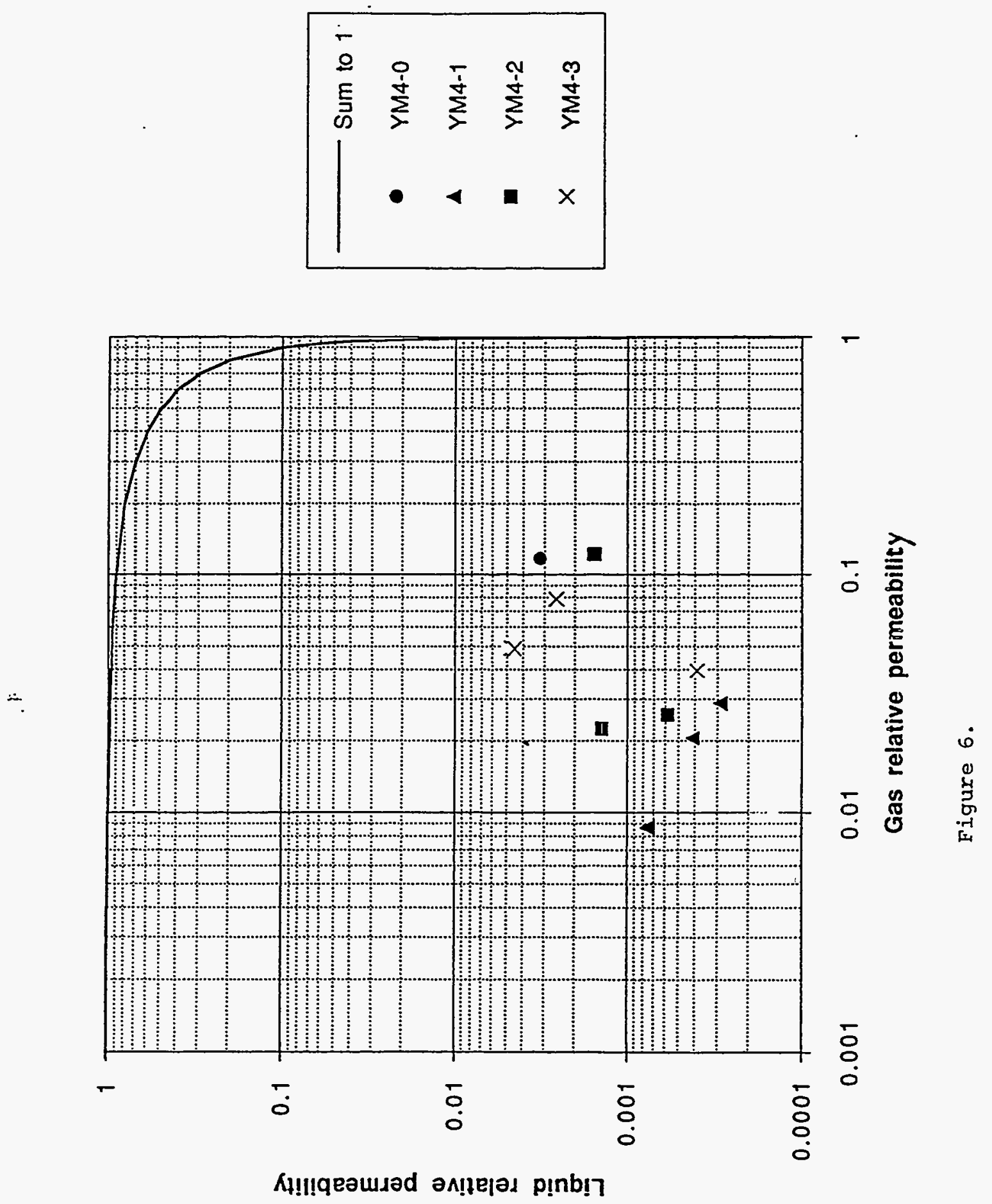
YM-3

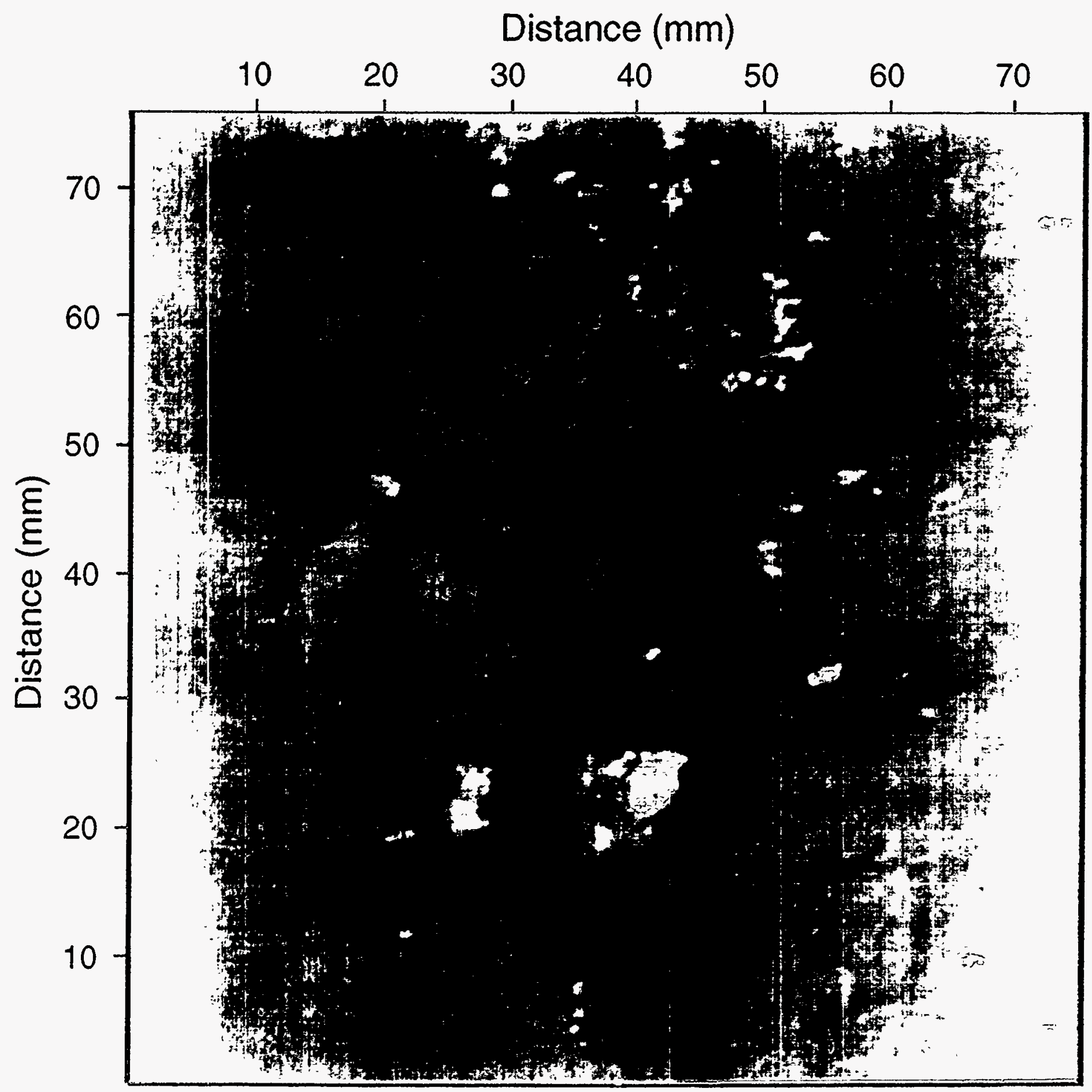

Figure 7. 
YM-4

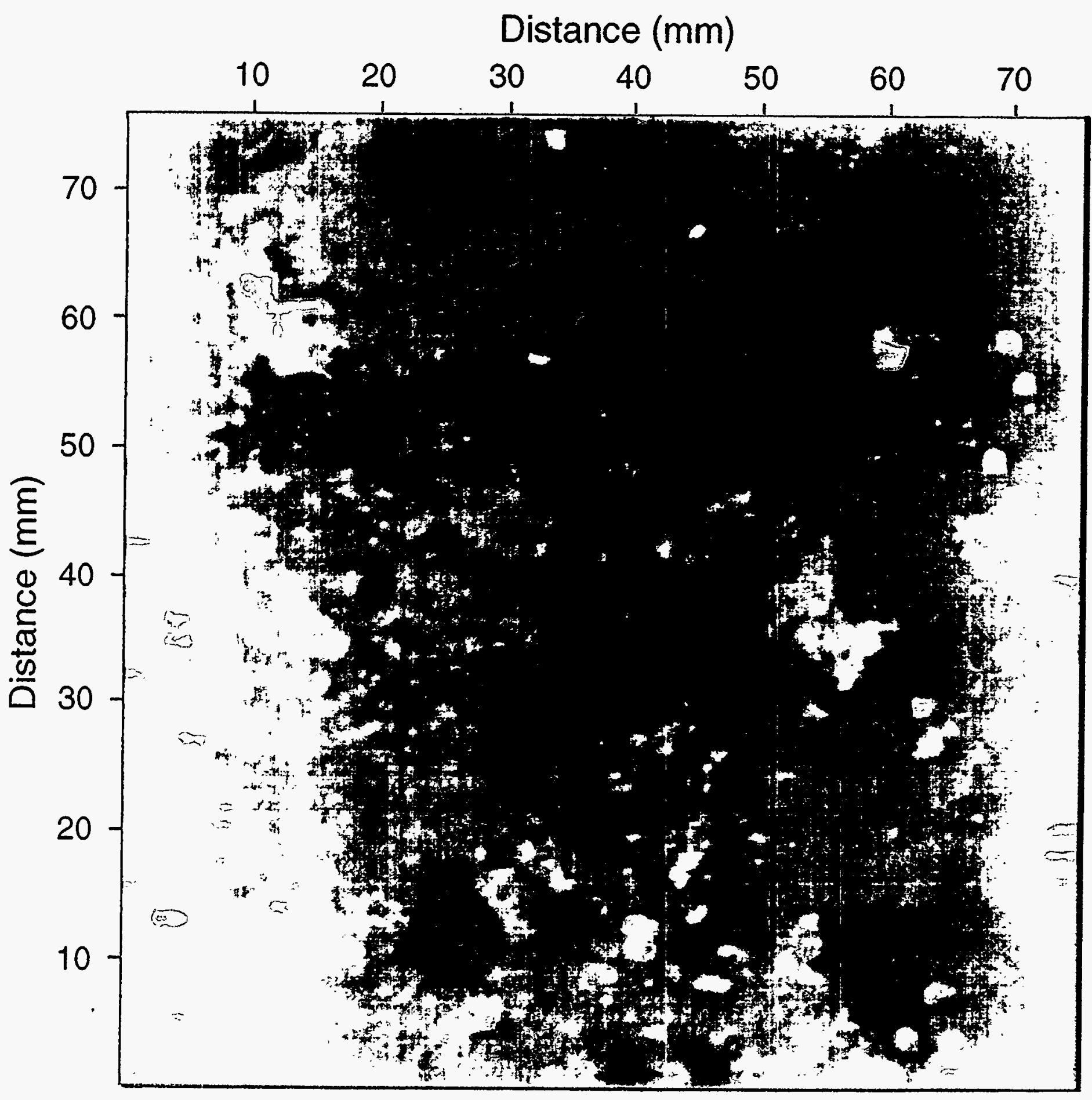

Figure 8. 
YM-3

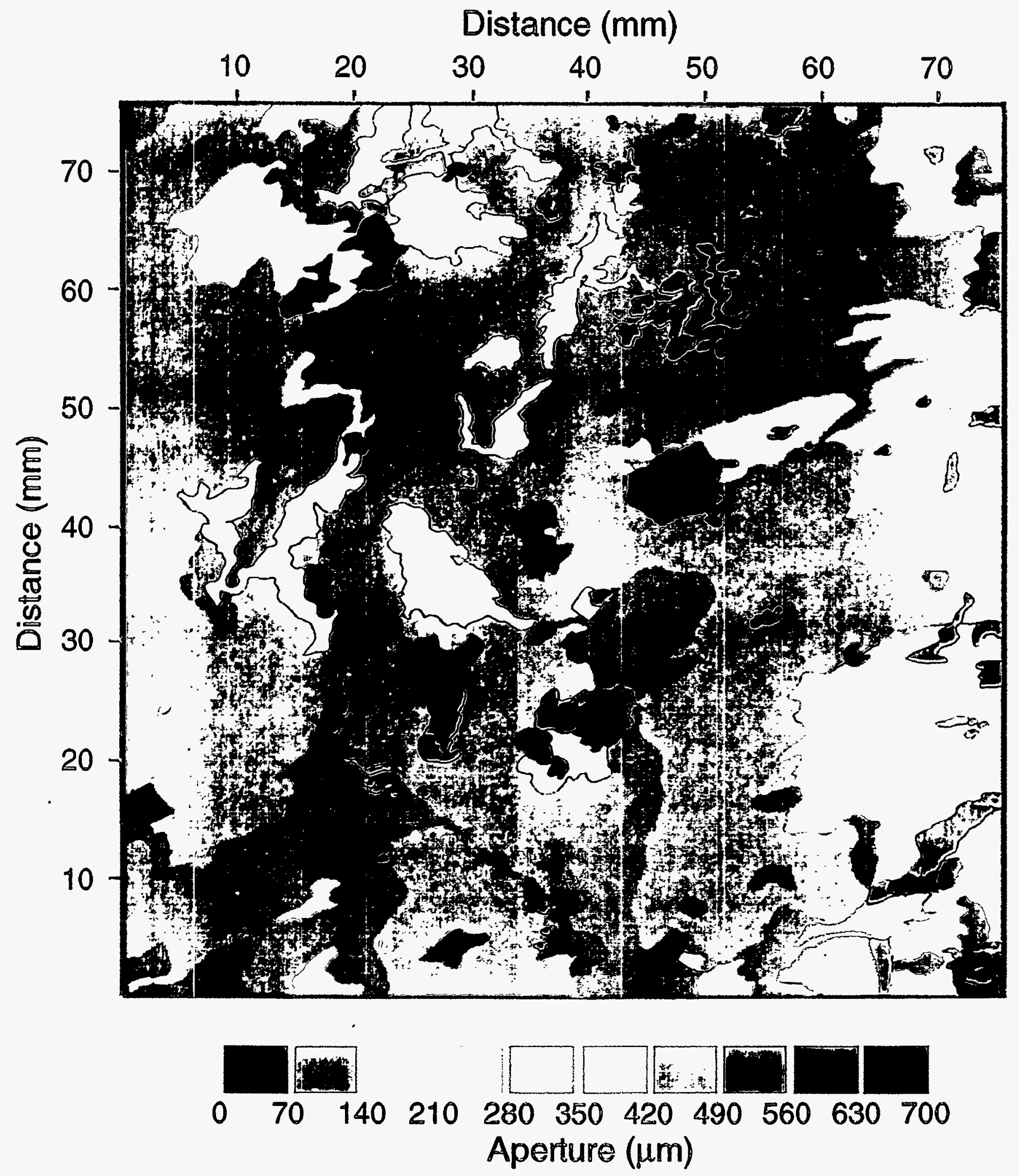

Figure 9. 


\section{(uri) asnued $\forall$}

00L 089 09S 06t 0Zt OSE 08Z OLZ Ot। OL 0
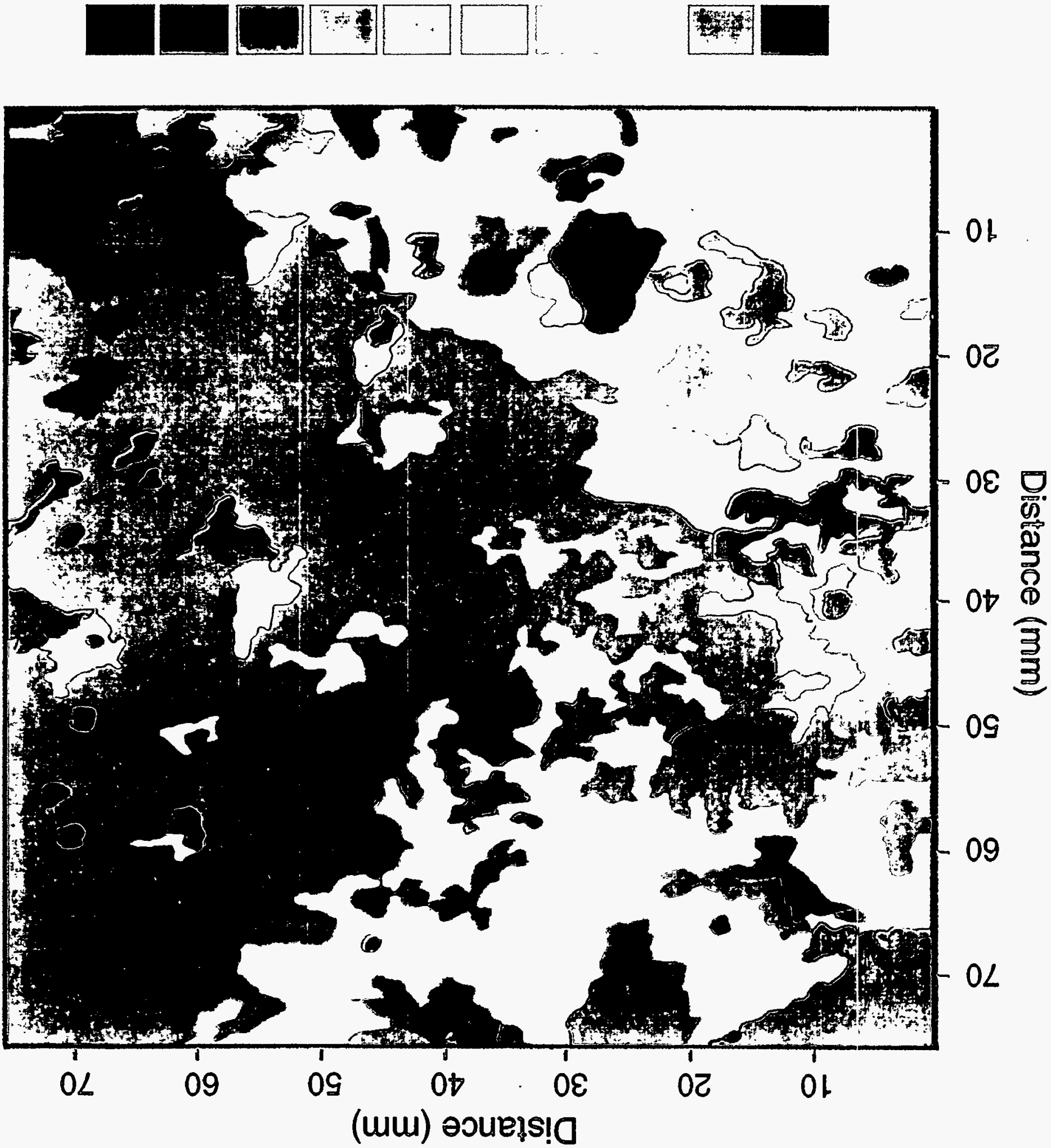


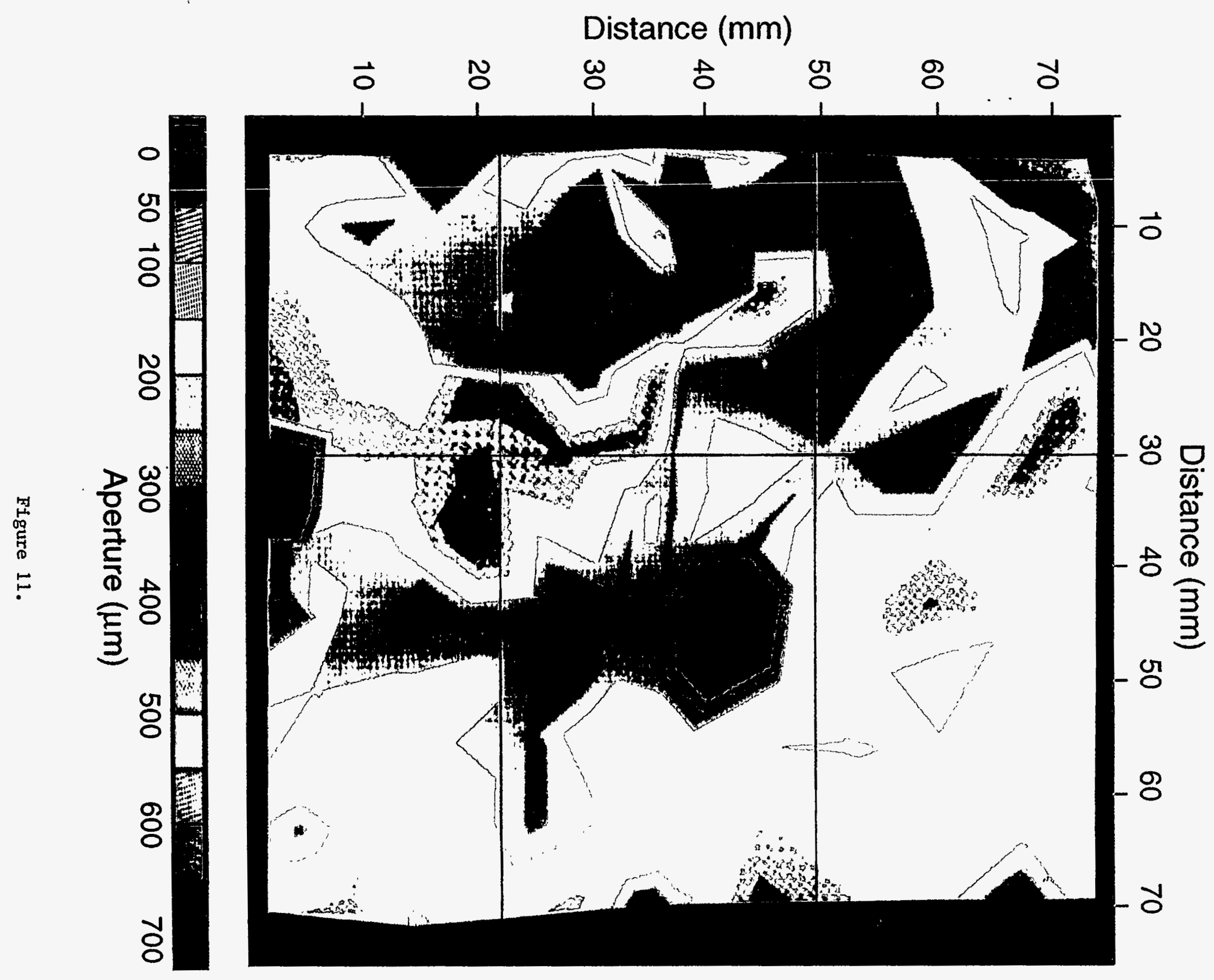




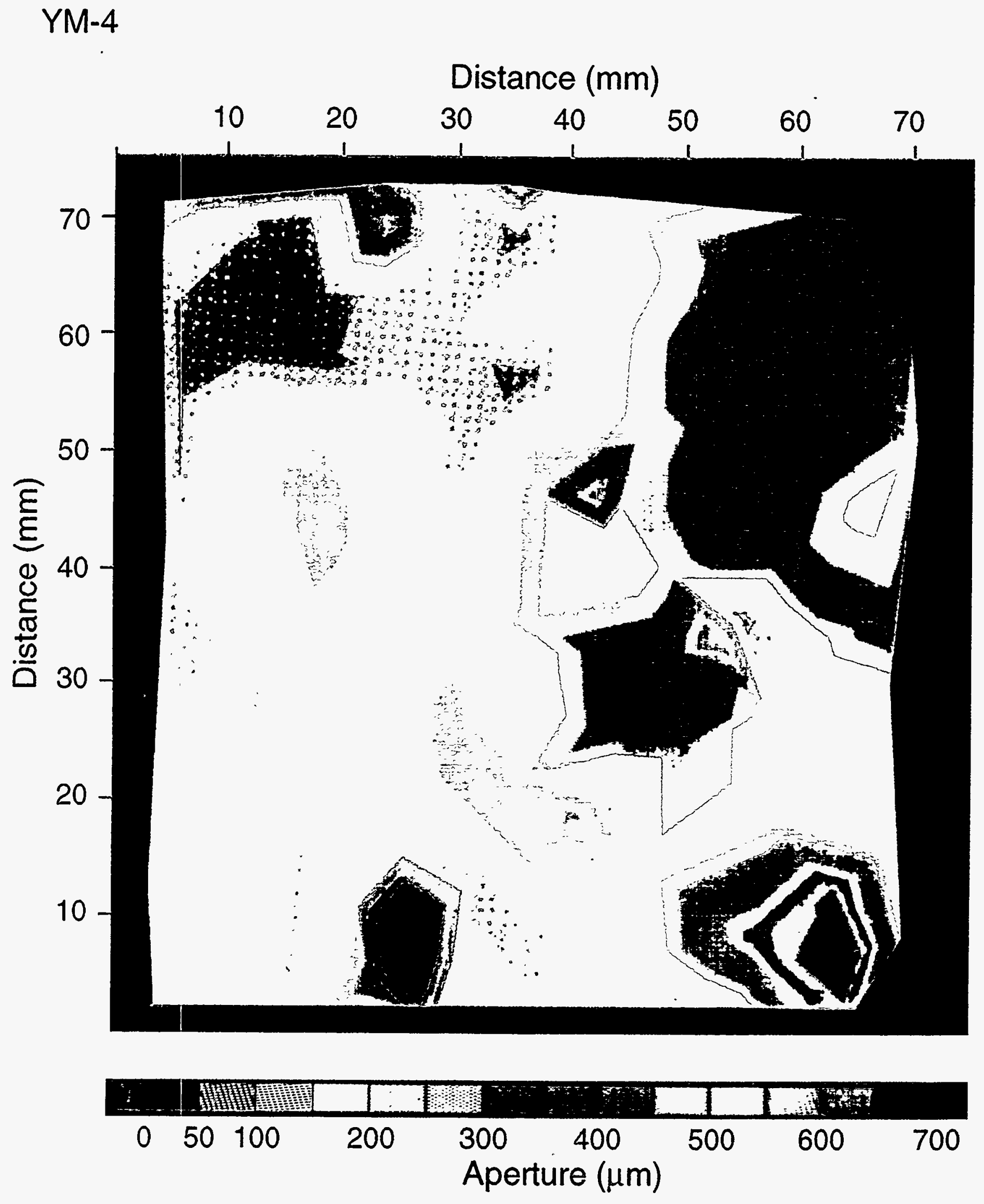

Figure 12. 


\section{Appendix A.}

\section{Raw Data}

These tables summarize the raw data from which all relative permeabilities can be calculated. 


\begin{tabular}{|c|c|c|c|c|c|c|c|c|c|c|c|c|c|c|c|c|c|c|c|c|c|c|c|}
\hline$\frac{0}{\frac{0}{0}} \frac{0}{0}$ & & & & 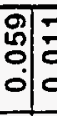 & : & & $\begin{array}{l}\mathbf{0} \\
0 \\
0 \\
0 \\
0\end{array}$ & \begin{tabular}{l|l|}
0 & \multicolumn{2}{|c}{} \\
0 & 0 \\
0 & 0 \\
0
\end{tabular} & & \begin{tabular}{l|l|l|} 
& 0 \\
0 & 0 \\
0 & 0 \\
0 & 0 \\
\end{tabular} & $\mid \begin{array}{lll} & 0 \\
0 & 0 \\
0 & 0 & 0 \\
0\end{array}$ & : & & 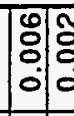 & ज़|: & \begin{tabular}{l|l|} 
& \multicolumn{1}{|c|}{} \\
0 & 0 \\
$\vdots$ & 0 \\
\end{tabular} & \begin{tabular}{|l|l|} 
& 0 \\
0 & 0 \\
0 & 0 \\
\end{tabular} & \begin{tabular}{|c|c|c|} 
\\
$\vdots$
\end{tabular} & \begin{tabular}{|l|l|} 
\\
0
\end{tabular} & & $\begin{array}{l}0 \\
\vdots \\
0 \\
0 \\
\end{array}$ & & :0 \\
\hline$\frac{.0}{\frac{0}{0}}$ & 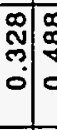 & 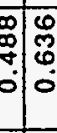 & $\left|\begin{array}{l}\mid \\
⿱ \\
0\end{array}\right|$ & 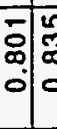 & & & 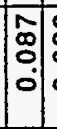 & & & & & & & बूa & ר̦: & & 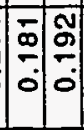 & पी: & $\begin{array}{l}0 \\
0 \\
0\end{array}$ & & $\mid$ & & \\
\hline 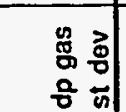 & 0 & \begin{tabular}{l|l}
0 \\
0 \\
0 \\
0 \\
0
\end{tabular} & : & $\begin{array}{l}0 \\
\hat{y} \\
0 \\
0\end{array}$ & $\left|\begin{array}{l}\mid \\
0 \\
0 \\
0\end{array}\right|$ & & : & & $\left|\begin{array}{l}\mid \\
0 \\
0 \\
0\end{array}\right|$ & & $\mid \begin{array}{l}0 \\
0 \\
0\end{array}$ & $\dot{0}$ & & $\left|\begin{array}{l}0 \\
0 \\
0 \\
0\end{array}\right|$ & $\mid$ & & \begin{tabular}{|l|l|l|l|l|l|}
0 & 0 \\
0 & 0 & 0 \\
0 & 0
\end{tabular} & 50 & \begin{tabular}{l|l|}
$\sigma$ & - \\
0 & 0 \\
0 & 0 \\
\end{tabular} & & $\begin{array}{l}\text { ठे } \\
0 \\
0\end{array}$ & & $\begin{array}{l}* \\
\mid\end{array}$ \\
\hline 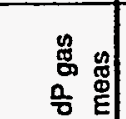 & 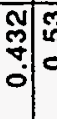 & 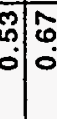 & & & 0 & & $=$ & & & & & & & 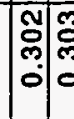 & 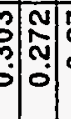 & & 命离 & & 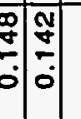 & & $\mid$ & & \\
\hline & & & & & & & & & & & & & & & & & & & & & & & \\
\hline 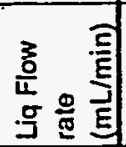 & 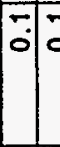 & & 0 & & & & o. & & 10 & & & & & 혐 & : & & $\mid \begin{array}{l}0 \\
0 \\
0\end{array}$ & : & \begin{tabular}{ll|l} 
\\
0
\end{tabular} & & $\dot{0}^{\circ}$ & & \\
\hline 言 & \begin{tabular}{l|l}
$-\overline{0}$ \\
0 \\
0 \\
0
\end{tabular} & \begin{tabular}{l|l}
0 & 0 \\
\hdashline & 0 \\
0 & 0 \\
0 & 0
\end{tabular} & & & & $\begin{array}{l}0 \\
0 \\
0 \\
0\end{array}$ & 尕 & & & & $\mid \begin{array}{l}|l| c \\
0 \\
0\end{array}$ & \begin{tabular}{l|l}
0 \\
0 \\
0
\end{tabular} & & 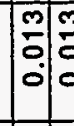 & \begin{tabular}{|c|c|}
0 \\
\end{tabular} & \begin{tabular}{l|l}
0 & 0 \\
\hdashline & $\frac{1}{0}$ \\
0 & 0 \\
0 & 0
\end{tabular} & \begin{tabular}{|l|l} 
& $\overline{0}$ \\
0 & 0 \\
0 & 0
\end{tabular} & 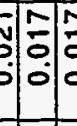 & 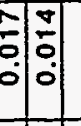 & & $\overline{0}$ & & \\
\hline & 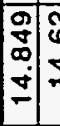 & $\dot{ \pm}$ & $\begin{array}{c}0 \\
0 \\
\dot{a} \\
\vdots\end{array}$ & & 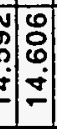 & & $\left.\mid \begin{array}{l}0 \\
0 \\
0 \\
0 \\
\square\end{array}\right]$ & & $\mid$\begin{tabular}{l}
0 \\
0 \\
0 \\
\hdashline \\
\hdashline
\end{tabular} & & $\mid \begin{array}{ll}0 \\
0 \\
0\end{array}$ & & & 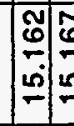 & 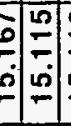 & & 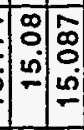 & & 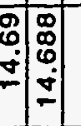 & 皇 & 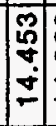 & & \\
\hline 름 & \begin{tabular}{|l|l} 
& 0 \\
0 & 0 \\
0 & 0 \\
0 & 0 \\
\end{tabular} & \begin{tabular}{l|l}
$\infty$ & \multicolumn{2}{c}{} \\
0 & 0 \\
0 & 0 \\
0 & 0
\end{tabular} & & & & & ô & & की & & $\mid \begin{array}{l}|l| l \\
0 \\
0\end{array}$ & 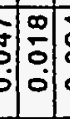 & & $\begin{array}{lll}\infty & \infty \\
0 & 0 & 0 \\
0 & 0 & 0 \\
0 & 0\end{array}$ & 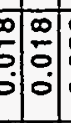 & & & & $\begin{array}{ll}0 \\
0 \\
0 \\
0 \\
0\end{array}$ & & |n & & \\
\hline & $\begin{array}{lll}9 & \\
6 & 4\end{array}$ & & की & & 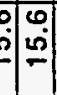 & 离 & 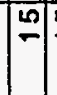 & & $=$ & & 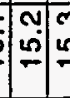 & $\begin{array}{ccc}0 \\
0 \\
0\end{array}$ & $\mid$ & 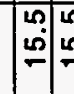 & 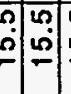 & 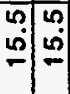 & $\mid$\begin{tabular}{c|c}
0 \\
$\stackrel{5}{6}$
\end{tabular} & $\begin{array}{llll}0 & 0 \\
ن & 0 & 0 & 0\end{array}$ & $\begin{array}{ll} \\
\dot{\forall} \\
\dot{\square}\end{array}$ & ? & $\mid \begin{array}{l}\infty \\
\dot{j} \\
\\
\end{array}$ & & \\
\hline 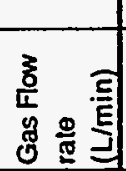 & $\left|\begin{array}{l}\mathbf{v} \\
0 \\
0 \\
0\end{array}\right| \begin{array}{c}0 \\
0\end{array}$ & 0 & s़े. & $\mid$ & $\begin{array}{l}: \\
: \\
:\end{array}$ & & : & \begin{tabular}{l|l}
0 & 0 \\
0 & 0 \\
0 & 0 \\
0 & 0 \\
0
\end{tabular} & : & \begin{tabular}{l|l}
\multirow{3}{*}{} & $\mathbb{T}$ \\
0 & 0 \\
0 & 0 \\
0
\end{tabular} & {$\left[\begin{array}{ccc}0 & 0 \\
0 & 0 \\
0 & 0 & 0\end{array}\right.$} & $\begin{array}{l}0 \\
0 \\
0\end{array}$ & & 0 & : & $\mid$\begin{tabular}{l|l}
0 \\
0 \\
0
\end{tabular} & 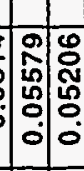 & : & 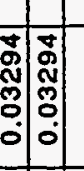 & & | & & 它 \\
\hline & 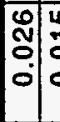 & : & : & \begin{tabular}{l|l} 
& 0 \\
0 & 0 \\
0 &
\end{tabular} & $\begin{array}{c}0.0 \\
0 \\
0\end{array}$ & & $\mid \begin{array}{l}0 \\
0 \\
0 \\
0\end{array}$ & 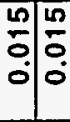 & $\mid \begin{array}{l}0 \\
0 \\
0 \\
0\end{array}$ & & 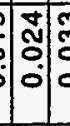 & \begin{tabular}{l|l|}
0 \\
0 \\
0 \\
0
\end{tabular} & & \begin{tabular}{l|l} 
& 0 \\
0 & 0 \\
0 & 0
\end{tabular} & \begin{tabular}{|l|l|}
0 & 0 \\
0 & 0 \\
0 & 0 \\
0 & 0 \\
0
\end{tabular} & \begin{tabular}{|l|l|} 
& \multirow{N}{N}{} \\
0 & $\mathbb{N}$ \\
0 & 0 \\
& 0 \\
\end{tabular} & 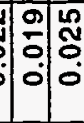 & 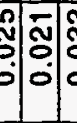 & & & $\left|\begin{array}{l}n \\
0 \\
0 \\
0\end{array}\right|$ & & \\
\hline & \begin{tabular}{|l|l} 
\\
0 \\
0 \\
0 \\
0 \\
0
\end{tabular} & $\begin{array}{l}\vec{\Xi} \\
\dot{\Xi}\end{array}$ & $\mid \begin{array}{c}0 \\
0 \\
0 \\
0 \\
0\end{array}$ & 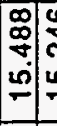 & 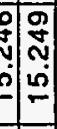 & & 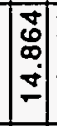 & 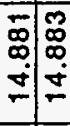 & $\mid \begin{array}{l}0 \\
0 \\
0 \\
0 \\
0\end{array}$ & & 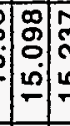 & 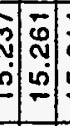 & & 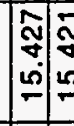 & 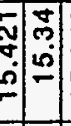 & 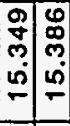 & 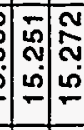 & 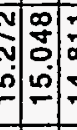 & & & $\mid$ & & \\
\hline & $\begin{array}{l}\text { Nิ: } \\
\text { Nิ: } \\
0 \\
0\end{array}$ & \begin{tabular}{l|l}
$\bar{y}$ & $\bar{g}$ \\
0 & 0 \\
0 & 0
\end{tabular} & & & & & 角 & & : & & $\left|\begin{array}{l|l}0 \\
0 \\
0\end{array}\right| \begin{array}{c}0 \\
0\end{array}$ & & & तิ & 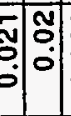 & \begin{tabular}{l|l}
$\mathbb{N}$ & \multirow{2}{*}{} \\
0 & 0 \\
0 & 0 \\
0 & 0
\end{tabular} & : & :ै: & 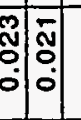 & & $\mid$\begin{tabular}{|}
$\mid$ \\
$\mathbb{N}$ \\
0 \\
0 \\
\end{tabular} & & \\
\hline & $\begin{array}{c}-5 \\
\vdots \\
0 \\
0\end{array}$ & 令 & $\begin{array}{l}: \\
0 \\
0 \\
0 \\
0\end{array}$ & $\left|\begin{array}{l}0 \\
\tilde{p} \\
0 \\
0\end{array}\right|$ & $\begin{array}{l}2 \\
0 \\
0 \\
0\end{array}$ & 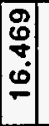 & $\begin{array}{c}\overline{0} \\
0 \\
0 \\
\end{array}$ & 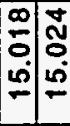 & $\mid \begin{array}{l}0 \\
\vdots \\
\vdots \\
0 \\
0 \\
0\end{array}$ & i. & 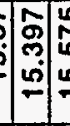 & 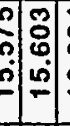 & & 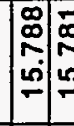 & 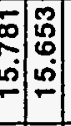 & 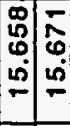 & 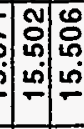 & : & 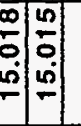 & & {$\left[\begin{array}{c}0 \\
0 \\
0 \\
0 \\
0 \\
0\end{array}\right]$} & & \\
\hline $\begin{array}{l}\tilde{z} \\
0 \\
0 \\
0\end{array}$ & 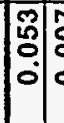 & 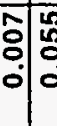 & : & 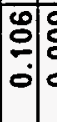 & 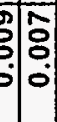 & & $\begin{array}{l} \\
0 \\
0 \\
0\end{array}$ & & : & & \begin{tabular}{l|l}
0 & 0 \\
0 & 0 \\
0 & 0
\end{tabular} & \begin{tabular}{l|l|l|} 
\\
5 \\
\end{tabular} & & 어요 & \begin{tabular}{l|l|}
0 \\
0 \\
0 \\
0
\end{tabular} & \begin{tabular}{|l|l}
$: 0$ \\
0 \\
0 & 0 \\
0 & 0 \\
0 & 0
\end{tabular} & 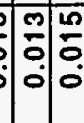 & $\frac{0}{0} \mid \frac{n}{0}$ & $\begin{array}{l}0 \\
0 \\
0 \\
0\end{array}$ & & $\mid$\begin{tabular}{|}
$\mid$ \\
0 \\
0 \\
0 \\
0
\end{tabular} & & \\
\hline $\bar{z}$ & {$\left[\begin{array}{l}0 \\
0 \\
0 \\
0\end{array} \mid\right.$} & 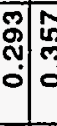 & : & $\mid \begin{array}{c}0 \\
0 \\
0 \\
0 \\
0 \\
0\end{array}$ & 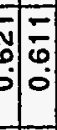 & & $\mid$ & & $\mid \begin{array}{l}\mid \bar{g} \\
\vdots \\
0\end{array}$ & \begin{tabular}{|l|l|} 
& 0 \\
& 0 \\
\end{tabular} & $\mid$\begin{tabular}{c|c}
0 \\
0
\end{tabular} & 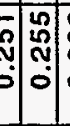 & & 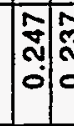 & : & 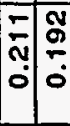 & $: \frac{6}{0}$ & ঢ) & $\begin{array}{l}: \\
: \\
: \\
0 \\
0\end{array}$ & & $\mid$ & & \\
\hline$\frac{5}{0} \frac{5}{5}$ & $\left(\begin{array}{c}\sigma \\
0 \\
0 \\
0\end{array}\right.$ & 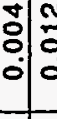 & : & $\left|\begin{array}{lll}n & 1 \\
0 \\
0 \\
0 \\
0\end{array}\right|$ & : & & o. & o: & : & 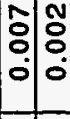 & : & : & & 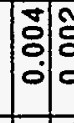 & 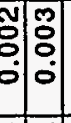 & \begin{tabular}{l|l}
0 \\
0 \\
0 \\
0
\end{tabular} & : & : & ס्: & & : & & \\
\hline$\frac{5}{0} \bar{g}$ & {$\left[\begin{array}{l}0 \\
0 \\
0 \\
0 \\
0\end{array} \mid\right.$} & : & & $\mid \begin{array}{l}0 \\
0 \\
0 \\
0\end{array}$ & & & {$\left[\begin{array}{l}0 \\
0 \\
0\end{array}\right.$} & & & & $\frac{2}{2}: 8$ & & & 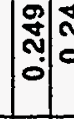 & 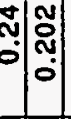 & $\mid$\begin{tabular}{c}
0 \\
$\substack{0 \\
\hdashline}$ \\
\hdashline
\end{tabular} & $: \frac{\$}{0}$ & $\left.\frac{n}{0}\right|_{0} ^{\infty} \mid$ & $\begin{array}{c}0_{0}^{\prime} \\
0 \\
0\end{array}$ & & के & & \\
\hline 2 & & & & & & & & & & & 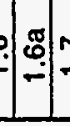 & & & $\left.\overline{\mathrm{s}}\right|_{\Omega} ^{\circ}$ & 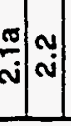 & ָָ & 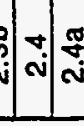 & 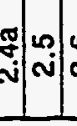 & \begin{tabular}{l|l|l} 
& 0 \\
\end{tabular} & & m & & \\
\hline
\end{tabular}




\begin{tabular}{|c|c|c|c|c|c|c|c|c|c|c|c|c|c|c|c|c|c|c|}
\hline $\begin{array}{l}\text { ExpF } \\
\text { Conditio } \\
n\end{array}$ & $\begin{array}{l}\text { Pcin } \\
\text { (psi) }\end{array}$ & \begin{tabular}{|l|} 
Pcin \\
sind \\
dov
\end{tabular} & $\begin{array}{l}\text { Pc out } \\
\text { (psi) }\end{array}$ & $\begin{array}{l}\begin{array}{l}\text { Pc out } \\
\text { stnd } \\
\text { dev }\end{array} \\
\end{array}$ & $\begin{array}{l}\mathrm{Pg} \text { in } \\
\text { (psi) }\end{array}$ & $\begin{array}{l}\mathrm{Pg} \text { in } \\
\text { sind dev }\end{array}$ & $\begin{array}{l}\mathrm{Pg} \text { out } \\
\text { (psi) }\end{array}$ & $\begin{array}{l}\text { Pg out } \\
\text { stnd } \\
\text { dev }\end{array}$ & $\begin{array}{l}\text { Gas flow } \\
\text { rate } \\
\text { (L/min) }\end{array}$ & $\begin{array}{l}\text { Pi in } \\
\text { (psi) }\end{array}$ & $\begin{array}{l}\text { Pl in } \\
\text { sind dov }\end{array}$ & $\begin{array}{l}\text { Pl out } \\
\text { (psi) }\end{array}$ & \begin{tabular}{|l|}
$\begin{array}{l}\text { Pl out } \\
\text { stind } \\
\text { dev }\end{array}$ \\
\end{tabular} & $\begin{array}{l}\text { dp liq } \\
\text { meas }\end{array}$ & $\begin{array}{l}\text { dp liq st } \\
\text { dev }\end{array}$ & \begin{tabular}{|l} 
Liq flow \\
rate \\
$(\mathrm{mL} / \mathrm{min})$ \\
\end{tabular} & \begin{tabular}{|l|}
$\mathrm{dP}$ gas \\
meas
\end{tabular} & $\begin{array}{l}\text { dp gas } \\
\text { st dev }\end{array}$ \\
\hline 0.1 & 0.226 & 0.017 & 0.218 & 0.018 & 15.426 & 0.021 & 15.24 & 0.017 & 0.095 & 15.263 & 0.028 & 15.059 & 0.019 & 0.16 & $\begin{array}{l}0.005 \\
\end{array}$ & 0.04 & 0.184 & 0.008 \\
\hline & & & & & & & & & & & & & & & & & & \\
\hline 1.1 & 0.432 & 0.008 & 0.391 & 0.008 & 15.658 & 0.02 & 15.34 & 0.016 & 0.0124 & 15.318 & 0.021 & 14.998 & 0.012 & .257 & .008 & 0.015 & 0.324 & 0.007 \\
\hline 1.2 & 0.545 & 0.008 & 0.552 & 0.014 & \begin{tabular}{|l|}
16.021 \\
\end{tabular} & 0.024 & 15.54 & 0.015 & 0.044 & 15.547 & 0.026 & 15.037 & 0.012 & 0.462 & 0.014 & 0.015 & 0.479 & 0.015 \\
\hline 1.3 & 0.698 & 0.011 & 0.713 & 0.018 & 16.617 & 0.022 & 15.96 & 0.024 & 0.0855 & 16.034 & 0.018 & 15.292 & 0.013 & 0.655 & 0.004 & 0.015 & 0.665 & 0.013 \\
\hline & & & & & & & & & & & & & & & & & & \\
\hline 2.1 & 0.2 & 0.005 & \begin{tabular}{|l|}
0.215 \\
\end{tabular} & 0.008 & 15.635 & 0.02 & 15.48 & 0.017 & 0.0155 & 15.521 & 0.017 & 15.309 & 0.014 & 0.139 & 0.005 & 0.015 & 0.156 & 0.008 \\
\hline 2.2 & 0.265 & 0.011 & 0.248 & 0.019 & 15.69 & 0.022 & 15.52 & 0.021 & 0.08 & 15.496 & 0.019 & 15.324 & 0.015 & 0.123 & 0.016 & 0.015 & 0.149 & 0.015 \\
\hline 2.3 & 0.38 & 0.007 & 0.38 & 0.004 & 15.97 & 0.022 & 15.61 & 0.017 & 0.0405 & 15.692 & 0.023 & 15.279 & 0.015 & 0.33 & 0.006 & 0.015 & 0.353 & 0.004 \\
\hline & & & & & & & & & & & & & & & & & & \\
\hline 3.1 & 0.305 & 0.006 & 0.306 & 0.007 & 15.769 & 0.022 & 15.5 & 0.014 & 0.0455 & 15.583 & 0.027 & 15.246 & 0.015 & .241 & .004 & 0.0075 & 0.26 & 0.009 \\
\hline 3.2 & 0.228 & 0.005 & 0.232 & 0.018 & 15.621 & 0.023 & 15.44 & 0.019 & 0.055 & 15.496 & 0.026 & 15.261 & 0.021 & 0.151 & 0.011 & 0.03 & 0.158 & 0.015 \\
\hline $3.3 \mathrm{a}$ & 0.152 & 0.005 & 0.154 & 0.006 & 15.62 & 0.02 & 15.4 & 0.016 & 0.04 & 15.543 & 0.018 & 15.297 & 0.013 & 0.183 & 0.003 & 0.066667 & 0.185 & 0.008 \\
\hline $3.3 b$ & 0.15 & 0.013 & 0.166 & 0.011 & 15.634 & 0.022 & 15.42 & 0.018 & 0.04 & 15.586 & 0.026 & 15.306 & 0.015 & 0.191 & 0.008 & 0.066667 & 0.186 & 0.01 \\
\hline
\end{tabular}

